\title{
Surface-Induced Dissociation Shows Potential to Be More Informative Than Collision-Induced Dissociation for Structural Studies of Large Systems
}

\author{
Vicki H. Wysocki, Christopher M. Jones, Asiri S. Galhena, \\ and Anne E. Blackwell \\ Department of Chemistry, Department of Biochemistry and Molecular Biophysics, University of Arizona, \\ Tucson, Arizona, USA
}

\begin{abstract}
The ability to preserve noncovalent, macromolecular assemblies intact in the gas phase has paved the way for mass spectrometry to characterize ions of increasing size and become a powerful tool in the field of structural biology. Tandem mass spectrometry experiments have the potential to expand the capabilities of this technique through the gas-phase dissociation of macromolecular complexes, but collisions with small gas atoms currently provide very limited fragmentation. One alternative for dissociating large ions is to collide them into a surface, a more massive target. Here, we demonstrate the ability and benefit of fragmenting large protein complexes and inorganic salt clusters by surface-induced dissociation (SID), which provides more extensive fragmentation of these systems and shows promise as an activation method for ions of increasing size. (J Am Soc Mass Spectrom 2008, 19, 903-913) @ 2008 American Society for Mass Spectrometry
\end{abstract}

$\mathrm{O}$ ver the past two to three decades, mass spectrometry (MS) has expanded significantly, from its early use as a technique for measuring the isotopes of elements and analyzing volatile compounds, to a technique that is now routinely used to study nonvolatile molecules and large macromolecular complexes. Increasingly, mass spectrometry and ion mobility/mass spectrometry are described as structural biology tools. Mass spectrometry has recently provided insights on posttranslational modifications [1], mono- and polydisperse subunit stoichiometry [2], subunit organization [3, 4], and noncovalent protein-ligand binding sites [5]. In addition to revealing structural information, mass spectrometry can be used to monitor dynamic processes, such as protein complex assembly [6], protein-substrate and protein-protein interactions $[7,8]$, and substratespecific conformational changes [9].

One of the limitations of current technology, however, is the fact that commercial instrumentation is still hampered by the amount of dissociation that can be induced from large biomolecular complexes. Often, MS has to be combined with many solution-based experiments $(\mathrm{H} / \mathrm{D}$ exchange plus digestion, chemical crosslinking plus digestion, limited proteolysis, solution disruption by changes in ionic strength) because the MS

Address reprint requests to Dr. Vicki H. Wysocki, University of Arizona, Department of Chemistry, 1306 E. University, Tucson, AZ 857-0041. E-mail: vwysocki@email.arizona.edu instruments commercially available do not provide extensive dissociation of these massive complexes. A typical dissociation result that is achieved is ejection of a monomer subunit as illustrated here (Figure 1) for a small heat shock protein (sHSP) dodecamer, consisting of 12 subunits each weighing $16.9 \mathrm{kDa}[8,10,11]$. The $16.9 \mathrm{kDa}$ monomer typically carries away a large percentage of the charge of the original complex with the remainder of the charge on the 11-mer that weighs 186 $\mathrm{kDa}$. Investigators have concluded that this behavior, which has been observed by several research groups for many different noncovalent protein complexes, happens because the low-energy collisions with a gas initiate unfolding of one of the protein subunits [12-14]. As this subunit unfolds, it gains surface area, thus allowing it to accept more charge. Eventually, when the unfolding protein and the remainder of the complex have about the same surface area and charge [15], the two can separate, leading to a result such as the one shown in Figure 1. Although this type of result does provide structural information, such as confirmation of the oligomeric state of the complex and information on which protein subunit is most easily ejected from the complex, it does not provide as much structural information as desired on the complex substructure. This complex, for example, is known from X-ray crystallography to exist as two stacked rings, each with six proteins, and is thought to be in equilibrium in solution with a dimer [16]. The CID spectrum, however, reflects 


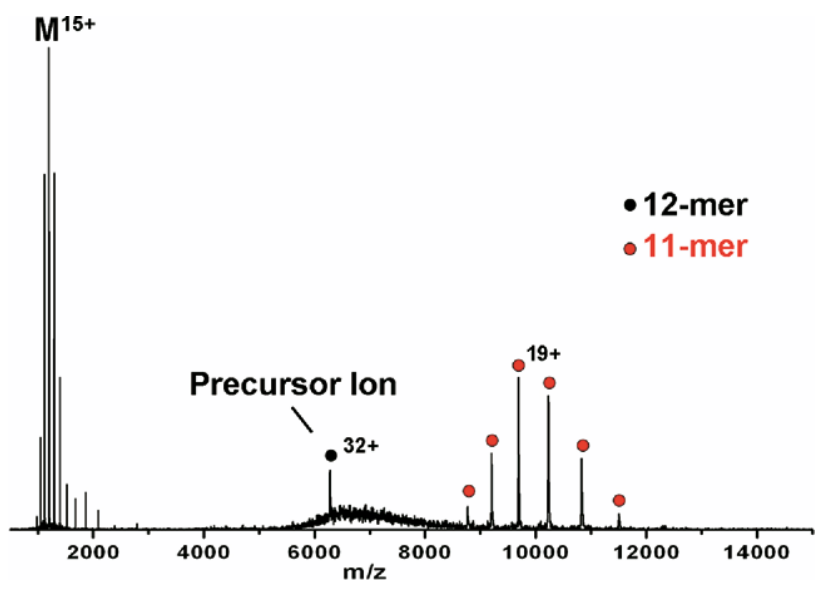

Figure 1. Collision-induced dissociation of dodecameric TaHSP16.9. At a collision energy of $3520 \mathrm{eV}$, the $32+$ dodecamer produces mainly monomer with an average of 15 charges and 11-mer with an average of 19 charges. Collision energy is listed as the product of voltage difference between the source hexapole and the gas-filled collision cell $(110 \mathrm{~V})$ and the $32+$ precursor ion charge state.

neither the presence of dimeric building blocks nor the stacked ring substructure.

The lack of extensive dissociation is likely the result of the limited amount of energy deposited into the large complex with each collision with the target gas, typically a low mass atomic target such as Ar. The extent of dissociation or even the extent of desolvation of a complex can be increased by using a more massive target gas such as Xe, suggesting that the efficiency of energy transfer is related to the mass of the target as expected [17-19]. It is appealing to be able to directly dissociate large complexes much more extensively than is now possible with collision-induced dissociation (CID) in commercial mass spectrometers. Other activation methods have been attempted, such as electron capture dissociation (ECD) or blackbody infrared radiative dissociation (BIRD), but they have not shown extensive breakup of large complexes [12, 20], although ECD has shown charge separation proportional to molecular weight, indicating that the ejected monomer remains mostly folded [20]. An alternative to methods previously studied is to collide the large complexes into a much more massive target, such as a surface. Surface-induced dissociation (SID) provides efficient kinetic to internal energy conversion, which might prove advantageous for fragmenting ions that approach or exceed the MDa size regime. The energytransfer efficiency in SID has been reported to vary with surface properties such as stiffness and mass of the terminal groups, indicating these factors likely contribute to the effective mass of the surface as a collision partner [21, 22]. Energy-transfer efficiency for fluorinated self-assembled monolayers (FSAMs) on gold has been reported to be between 20 and $28 \%$ $[21,23]$. The influence of ion size on the SID energytransfer efficiency, however, has been debated in the literature and is not entirely understood [24-26], especially for systems as massive as noncovalent proteins. Nonetheless, collision with a surface should still be a more efficient process than collision with a gas for which efficiencies less than $0.01 \%$ per collision have been reported for large protein complexes [9]. SID of a few protein complexes has suggested that alternative ion activation methods may provide a way to extract meaningful structural data from the gas-phase fragmentation of protein complexes [27-30].

One way to improve our understanding of the dissociation of large, noncovalent molecules may be through the study of other, comparatively simple, and well-characterized macromolecular systems, such as inorganic salt clusters. Clusters have received significant experimental and theoretical attention during the past two decades. They are an important group of structures because they span the chemical and physical gap between discrete atoms or molecules and solid materials and provide clues to the transitions between the condensed and gaseous states of matter [31]. Furthermore, these systems allow an understanding of several physical/chemical processes including phasetransition phenomena, crystal growth, chemical catalysis, and thin-film formation [32, 33]. In contrast to proteins and their noncovalent complexes, clusters are simple structural moieties with minimum structural complexity. They are structures composed of small numbers of heavy atoms, whereas protein complexes are structures composed of large numbers of light atoms. These represent two extremes, in the sense that, for similar masses of a protein and a salt cluster system, the protein would always possess a higher number of internal degrees of freedom. Their simplicity makes salt clusters ideal for comparing fundamental differences between SID and CID for large molecules. Among the different types of cluster systems, alkali halide clusters have been extensively studied by mass spectrometry, especially singly charged positive-ion clusters. The general formula for theses clusters can be given as $(\mathrm{MX})_{\mathrm{n}} \mathrm{M}^{+}$[34-37], where $\mathrm{M}$ and $\mathrm{X}$ represent the cation and anion of the molecule. The alkali halides are known to generate clusters with extraordinary stability, the most prevalent of which correspond to stable cubic-like crystal structures (magic numbers) [38]. Previous CID studies of these clusters revealed the formation of mass stripped products attributed to the removal of neutral MX [39-43]. An important question that can be addressed by studying these systems is the influence of cluster size on fragmentation. CsI has been shown to form clusters consisting of up to $350 \mathrm{CsI}$ molecules [44]. This provides a framework for contrasting different ion activation methods as a function of ion size, and can help to define the advantages of dissociating other large, noncovalent systems via surface collisions.

This article describes recent advances in the application of surface-induced dissociation as a complementary tool for the direct dissociation of large complexes. 
Several examples are given, including protein complexes with different oligomeric substructures and singly and doubly charged CsI clusters. We also show that the extent of fragmentation increases with increasing collision energy, suggesting that SID of large complexes generally follows the typical expectations of kinetic theory of mass spectrometry [17, 45].

\section{Experimental}

\section{Materials and Methods}

Materials. Cesium iodide, equine cytochrome $c$, human transthyretin (prealbumin), jack bean concanavalin A, and human hemoglobin were purchased from Sigma-Aldrich Co. (St. Louis, MO, USA). Recombinant human Creactive protein, expressed in Escherichia coli and serum amyloid $\mathrm{P}$ component from human serum were purchased from EMD Chemicals, Calbiochem product brand (Gibbstown, NJ, USA). Small heat shock proteins Ta16.9 (wheat), Ps18.1 (garden pea), and AtHSP18.5 (Arabidopsis) were expressed in E. coli, and were generously provided by Prof. Elizabeth Vierling and coworkers at the University of Arizona. Ammonium acetate was purchased from Spectrum Chemicals \& Laboratory Products (Gardena, CA, USA). Micro Biospin columns for buffer exchange were purchased from Bio-Rad (Hercules, CA, USA). Gold surfaces were purchased from Evaporated Metal Films (Ithaca, NY, USA) and 2-(perfluoroctyl)-ethanethiol was synthesized by the Chemical Synthesis Facility at the University of Arizona.

Mass spectrometry. For the CsI salt cluster experiments, samples were sprayed out of a home-built nano-ESI source. The concentrations of the salt cluster samples were typically in the range of $20-50 \mathrm{mg} / \mathrm{ml}$ and sprayed out of 50:50 MeOH: $\mathrm{H}_{2} \mathrm{O}$. For the noncovalent protein complexes, samples were buffer exchanged into $200 \mathrm{mM}$ ammonium acetate ( $\mathrm{pH} 7)$ using microcentrifuge columns or, in the case of lyophilized samples, dissolved directly into ammonium acetate. The samples were loaded into glass capillaries pulled in house (P-97 micropipette puller, Sutter Instruments, Novato, CA, USA) to a final tip diameter of $1-5 \mu \mathrm{m}$. A platinum wire was inserted into the glass capillary and a voltage of 1.5 to $2.0 \mathrm{kV}$ was applied to electrospray the ions. The cone voltage was varied between 50 and $200 \mathrm{~V}$ until optimum ion transmission was obtained. No heating or desolvation gas was used with nano-ESI.

All experiments were conducted on a modified Q-ToF II mass spectrometer (Micromass/Waters, Manchester, UK), previously described [28]. Briefly, an in-line SID device was installed in between the quadrupole mass analyzer and hexapole gas-collision cell to allow direct comparisons of CID and SID on the same instrument. The SID device, which includes a surface holder, ion beam deflectors, and focusing lenses, is about $45 \mathrm{~mm}$ long, and was inserted by removing the transport hexapole following the collision cell. The collision cell was moved closer to the entrance of the ToF to make room for the SID device. For experiments involving small heat shock proteins, a shortened, $13 \mathrm{~cm}$ collision cell (Waters Corporation) replaced the traditional 18.5 $\mathrm{cm}$ collision cell to accommodate the SID device without removing the transport hexapole. This allowed the conventional ion optics to remain in place and facilitated the use of higher gas pressures within the collision cell while limiting detrimental pressure increases in the adjacent ToF region. Although both collision cells could be used to transmit product ions over the entire $\mathrm{m} / \mathrm{z}$ range, transmission efficiency of high $\mathrm{m} / \mathrm{z}$ product ions generated by either CID or SID was enhanced with the $13 \mathrm{~cm}$ collision cell. This presumably arises from the use of higher gas pressures necessary for collisional focusing of high $\mathrm{m} / \mathrm{z}$ product ions. The instrument was operated in one of two modes: one that allows ion transmission through the SID apparatus without hitting the surface for single-stage MS and CID experiments or, alternatively, surface collision mode in which ions are deflected into the surface for SID experiments. This allowed direct comparison between the two ion activation methods under identical instrument conditions and similar observation time frames.

In CID mode, the experiments were performed using argon (Ar) as the collision target. The pressure was measured in the quadrupole analyzer chamber and typically maintained between 1 and $6 \times 10^{-4}$ mbar (the actual pressure in the collision cell is different from the quadrupole chamber pressure because there is no pressure gauge connected directly to the collision cell). For SID experiments, FSAM surfaces were used as the collision target. The FSAM surfaces were prepared on $18 \times 12-\mathrm{mm}$ glass surfaces, coated with a 10 - $\AA$ layer of titanium followed by a 1000- $\AA$ layer of gold (Evaporated Metal Films Corp., Ithaca, NY, USA). A detailed experimental procedure for the surface preparation is given elsewhere [46, 47]. The collision cell was operated either without Ar gas with the collision cell serving solely as a hexapole ion guide, or with Ar gas for enhanced collisional focusing of high $\mathrm{m} / \mathrm{z}$ product ions. The collision voltage for the CID mode was controlled by adjusting the DC offset of the source hexapole between 0 and $200 \mathrm{~V}$, relative to the collision cell (grounded). For SID, the collision voltage was varied between 0 and $190 \mathrm{~V}$ by setting the DC offset (10-200 V) of the source hexapole with respect to the surface voltage $(\sim 10-20 \mathrm{~V})$. The actual collision voltage was calculated by subtracting the difference between these two voltages. All laboratory collision energies are listed as the product of the voltage difference times the precursor ion charge state.

Mass spectra were acquired under conditions optimized for the transmission of salt clusters and noncovalent protein complexes. Pressure in the source region of the instrument was raised by closing off the vacuum line to the rotary pump as described elsewhere [44]. Ions were selected for tandem mass spectrometry ex- 
periments with an extended mass range quadrupole and accelerated into either the surface or the gas-filled collision cell.

\section{Results and Discussion}

An extended $m / z$ range QToF was used to perform the experiments described. This general type of instrument has been used for much of the work reported on noncovalent protein and protein-ligand complexes in the literature. The instrument makes use of nanoelectrospray ionization that allows complexes to be sprayed intact into the gas phase. The extended $m / z$ range of the quad allows selection of very large complexes (e.g., ribosomes at 2.3 MDa have $m / z$ in excess of 20,000) [48-50].

\section{CsI Clusters}

CsI clusters were used to compare CID and SID. From the experimental point of view, clusters are relatively easy to form, and their ionic bonding character has allowed the development of simple models, making them ideal systems for comparing the two activation methods. Furthermore, CsI provides a simpler system than protein complexes because the major losses ex- pected all involve combinations of just two atoms. Figure 2 shows surface-induced and collision-induced dissociation spectra of $(\mathrm{CsI})_{13} \mathrm{Cs}^{+}$at an SID collision energy of $50 \mathrm{eV}$ (a) and at CID collision energies of 30, 40, 60, and $80 \mathrm{eV}$ (b). There may be some overlapping doubly charged ion selected, but if so, it is of low relative abundance. The dominant fragments detected in CID and SID correspond to losses of neutral CsI. SID shows more extensive dissociation than does CID, as expected for a more massive target. Another significant difference between the two ion activation methods is that with SID, there is an enhancement of the $(\mathrm{CsI})_{2} \mathrm{Cs}^{+}$ cluster formation. With CID, this fragmentation channel is limited or completely inaccessible. A similar observation was reported for small CsI cluster systems in a sector instrument with CID as the method of activation [51]. In contrast, SID allows the formation of $(\mathrm{CsI})_{2} \mathrm{Cs}^{+}$ via loss of multiple neutral CsI units. This loss is probably associated with higher energy onsets that only SID could provide under the given instrument operating conditions. Despites these minor differences, CID and SID of small, singly charged CsI clusters are largely similar with both activation methods providing extensive dissociation.

Figure 3 shows collision-induced and surface-induced dissociation spectra of $(\mathrm{CsI})_{43} \mathrm{Cs}_{2}{ }^{++}$at several collision

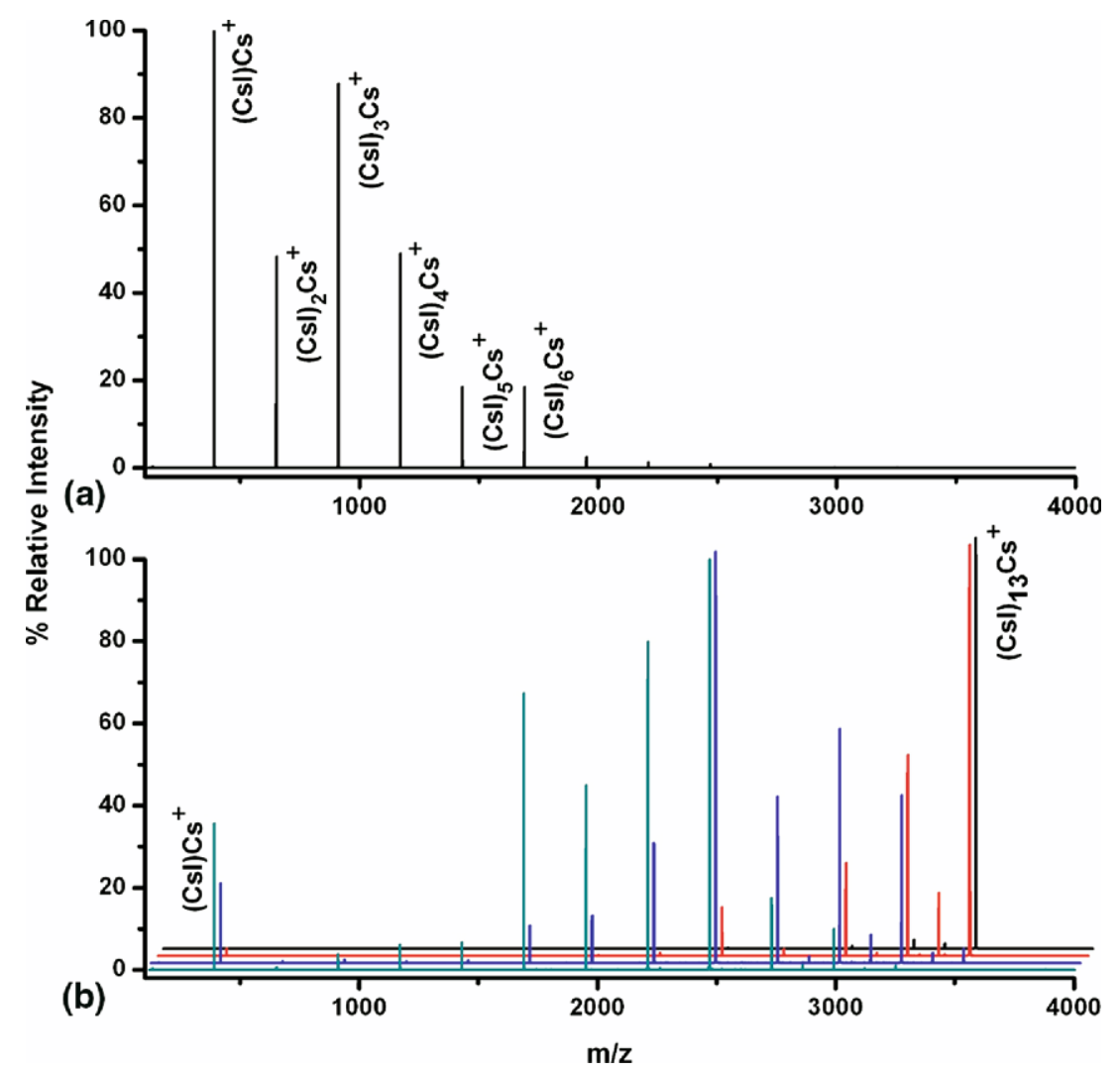

Figure 2. SID (a) and CID (b) spectra of $(\mathrm{CsI})_{\mathrm{n}=13} \mathrm{Cs}^{+} /(\mathrm{CsI})_{\mathrm{q}=26} \mathrm{Cs}^{2+}$ in a Q-TOF mass spectrometer. The laboratory collision voltages of 30, 40, 60, and $80 \mathrm{~V}$ were used for CID (from back to front of the waterfall plot) at analyzer pressure of $8 \times 10^{-5}$ mbar. The SID spectrum was collected at a collision voltage of $50 \mathrm{~V}$. 


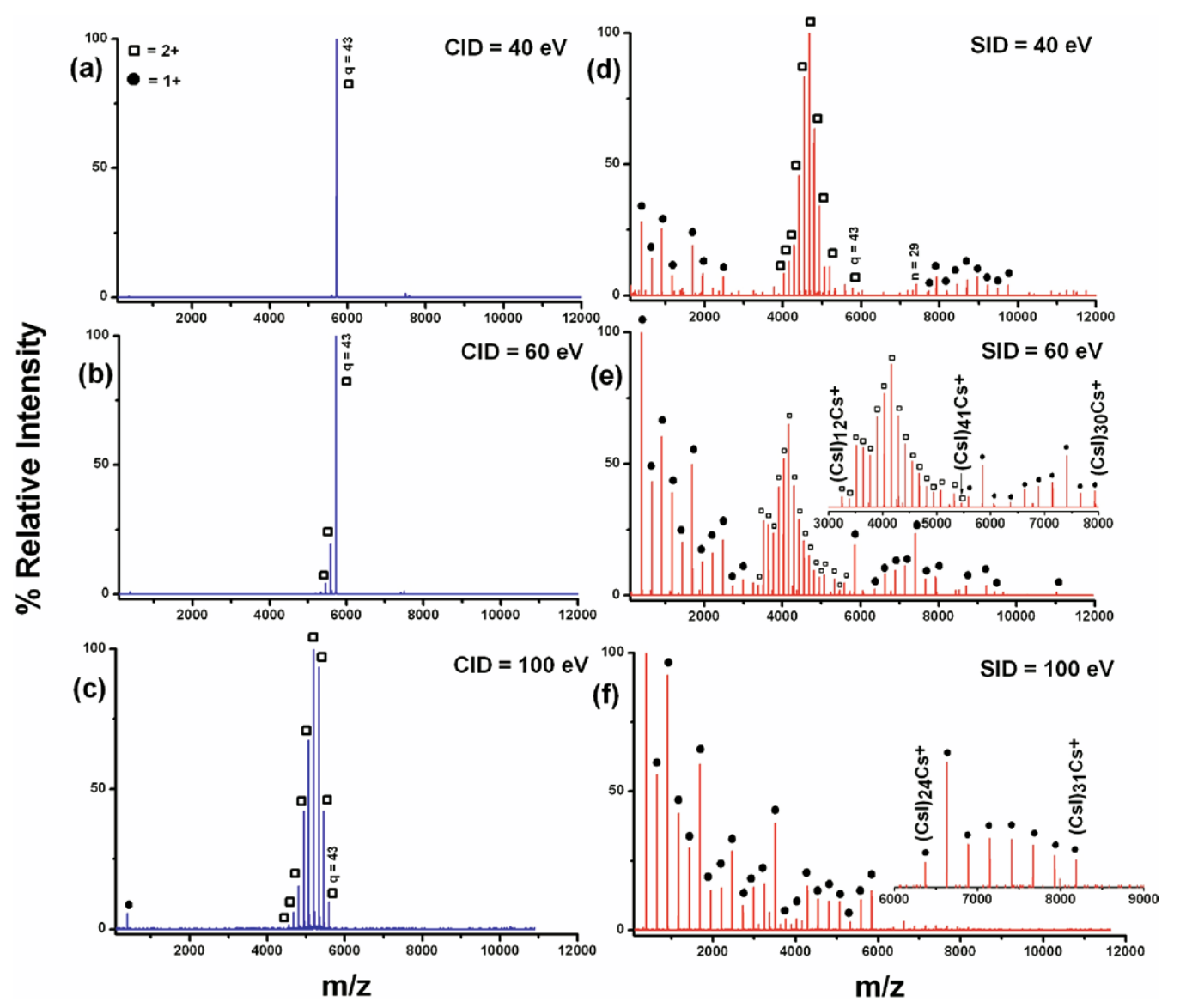

Figure 3. Comparison of CID (left panel) and SID (right panel) spectra of the doubly charged $(\mathrm{CsI})_{43} \mathrm{Cs}_{2}{ }^{++}$cluster. Inset in SID collision energy $60 \mathrm{eV}$ shows two distinct charge distributions: doubly and singly charged. SID at a collision energy of $100 \mathrm{eV}$ shows predominantly singly charged fragments. singly charged cesium iodide cluster fragments; $\square$, doubly charged cesium iodide cluster fragments.

energies. $(\mathrm{CsI})_{43} \mathrm{Cs}_{2}{ }^{++}$is a doubly charged cluster with nominal mass of 11,437 Da. This cluster carries significantly higher mass per unit charge, compared to the $(\mathrm{CsI})_{13} \mathrm{Cs}^{+}$cluster system. As shown in Figure 3 the CID $(\mathrm{a}-\mathrm{c})$ and SID $(\mathrm{d}-\mathrm{f})$ spectra are noticeably different. The CID spectra show a dominant fragmentation pathway by which neutral $(\mathrm{CsI})_{\mathrm{n}}$ units are lost (Scheme 1) to

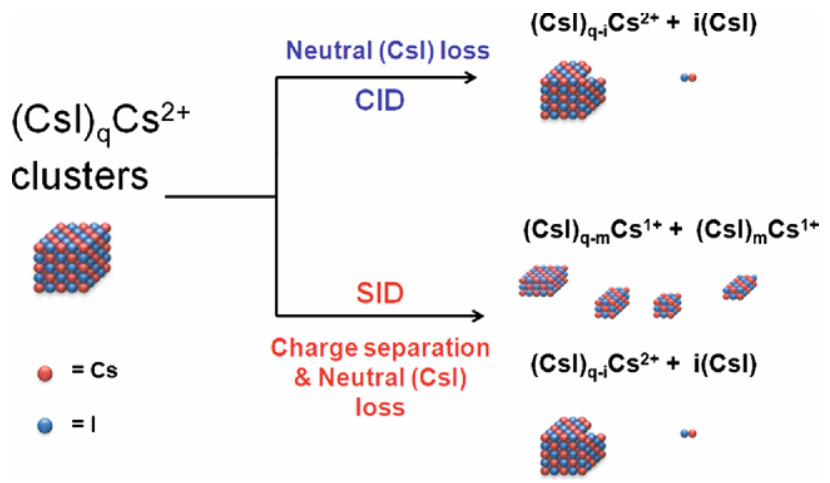

Scheme 1. Dissociation channels observed for the fragmentation of $(\mathrm{CsI})_{\mathrm{q}} \mathrm{Cs}^{2+}$ clusters. CID leads solely to consecutive losses of neutral CsI, whereas access to an additional charge separation pathway is provided by SID. produce doubly charged fragments from the doubly charged precursor.

SID, however, shows clear evidence of charge separation, producing dominantly singly charged fragments from a doubly charged precursor ion in addition to the loss of neutral (CsI) $)_{\mathrm{n}}$ units (Figure $3 \mathrm{~d}-\mathrm{f}$ ). Although CID shows neutral CsI loss as the most dominant fragmentation pathway, a second fragmentation pathway involving loss of singly charged $(\mathrm{CsI}) \mathrm{Cs}^{+}$was also evident, but to a very low extent. Neutral loss and fission are two competing processes, where the probability of each is dependent on energy availability and cluster size. With CID, the neutral loss process happens to be the most dominant and is driven by the size of the cluster and the limited access to high-energy pathways. This phenomenon can be explained with the help of the two-body interaction theory $[52,53]$. The formation of a doubly charged cluster can be considered as a product of a fusion process (fusion of two singly charged clusters). As one would expect, there is a long-range repulsive force between two charged clusters. However, as the two fragments are brought within the chemical bonding distance, the cluster should transform from unstable to a kinetically stable (or metasta- 
ble) cluster [54]. Martin calculated lowest possible energy configurations for doubly charged $\mathrm{NaI}$ clusters and showed a clear trend in which cluster stability increases with cluster size. In other words, the energy barrier preventing the most stable configuration from undergoing Coulombic dissociation increases as the size of the cluster increases [54]. Upon activation, if the added excess energy is sufficient to overcome this energy barrier, the cluster would undergo a fission process, producing charge-separated products. With $(\mathrm{CsI})_{43} \mathrm{Cs}_{2}{ }^{++}$, multiple-collision CID does not supply sufficient energy to overcome the barrier for the fission process to occur, even at the highest attainable collision energies. However, it still provides enough energy to eject neutral $(\mathrm{CsI})_{\mathrm{n}}$ units generating doubly charged mass-stripped product clusters (the doubly charged products still have large enough masses to be stable product clusters). Previous CID studies published by Cooks and coworkers [55] on doubly charged $\mathrm{NaI}$ cluster systems have also revealed a similar fragmentation pattern, where high-mass $\mathrm{NaI}$ clusters predominantly dissociated by loss of neutral $\mathrm{NaI}$ units and low-mass clusters dissociated by charge splitting. For these experiments we propose that SID deposits higher internal energy into the projectile ion, enabling it to overcome the energy barrier for the fission process. This claim is supported by breakdown curves for small CsI clusters, in which it is evident that the dissociation onset for any given fragment ion occurs at a lower laboratory collision energy by SID relative to CID. This explains the observation of abundant charge-separated (split) products in the SID spectra. Another striking effect observed in the SID spectra was the observation of ion intensity enhancement of certain fragment ions. These fragments are "magic number" clusters [35, 56-60], corresponding to symmetrically stable cubic crystal structures with lattices of $3 \times 3 \times 3,3 \times 3 \times 5,5 \times 5 \times$ 5 , and so forth (Scheme 1). In the event of collision on the surface, clusters relieve the stress of impact by cleaving along the lowest energy plane(s), leading to the formation of stable cubic crystal structures. Previous impact-induced dissociation studies of similar alkalihalide systems with graphite and silicon surfaces by Whetten and coworkers [61-63] also revealed similar fragmentation behavior. With our Q-TOF SID configuration, we were able to fragment CsI clusters larger than those previously reported, and compare their dissociation by both CID and SID. Overall, CID could readily access the low-energy neutral loss dissociation pathway to produce mass-stripped doubly charged cluster fragments but not the high-energy fission process. SID, in contrast, could access both competing pathways, offering more extensive fragmentation of the precursor ion cluster.

\section{Protein Complexes}

We previously reported the CID and SID spectra of cytochrome $c$ dimers [30]. Other investigators had shown that CID of the 11+ charge state of cytochrome $c$ leads to dominant $8+$ and $3+$ monomers $[13,64,65]$. As shown in Figure 4, SID over a broad range of collision energies instead leads to formation of $5+$ and $6+$ monomers, the charge states expected if 11 charges are split between two equivalent subunits. The different charge distributions detected are consistent with an unfolding mechanism for CID (monomer unfolding leads to charge enrichment of one of the subunits) and break-up of the complex by SID with greatly reduced unfolding, leading to a monomer with approximately the number of charges that would be obtained if the complex simply dissociates and shares the charge equally among subunits. This has been observed for several complexes investigated, including the $25+$ pentamer of serum amyloid P component (SAP) shown in Figure 5; when activated by CID this protein produces monomer with an average charge of 10.3 and tetramer with an average charge of 14.4. When activated by SID, however, only monomer is observed with an average charge state of 5.3 , or about $1 / 5$ of the precursor ion charge. This charge state distribution is consistent with dissociation of the $25+$ pentamer into five chargeequivalent monomers, allowing for slight variations in the charge uniformity of subunits within the pentameric precursor. Dimeric product ions are also observed in the SID spectrum. Again, the charge states of these products are proportional to their molecular weight,

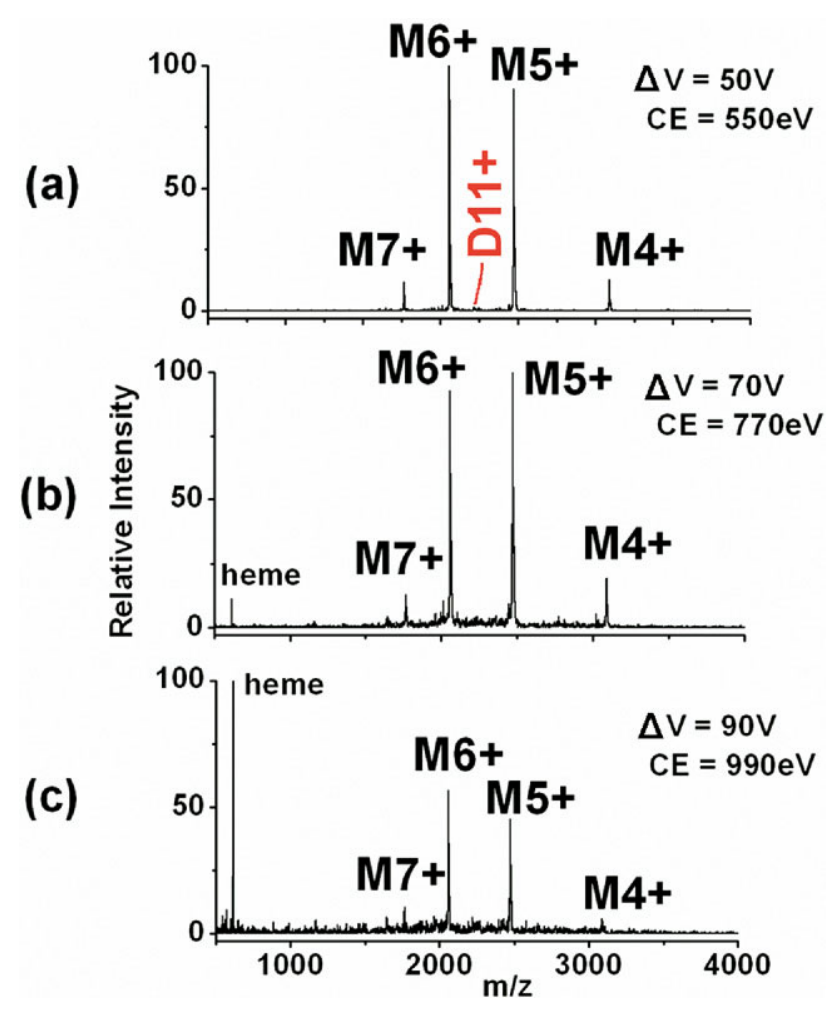

Figure 4. Energy-resolved SID of the 11+ dimer of cytochrome $c$. The dimer $(\mathrm{D} 11+)$ dissociates into monomers with an approximately equal partitioning of the precursor ion charge, regardless of the SID collision energy. Monomer product ions are labeled with an $\mathrm{M}$ followed by their respective charge state (Figure modified from supplemental figure in Smith et al. [22].) 
retaining about $2 / 5$ of the precursor ion charge. In addition, both the CID and SID spectra show losses corresponding to the sialic acid group of the nonasaccharide, attached to Asn-32 of each subunit.

Interestingly, CID of SAP shows unusual covalent fragmentation of the protein backbone at the same collision energy used to remove a single, noncovalently bound subunit. Around $1500 \mathrm{~m} / \mathrm{z}$ several protein backbone fragments corresponding to $\mathrm{y}_{40}{ }^{3+}, \mathrm{y}_{30}{ }^{2+}$, and $\mathrm{y}_{28}{ }^{2+}$ are observed. Although we have previously observed covalent fragment ions at sufficiently high collision energies (see Figure 6 and discussion thereof), these fragments have always appeared to correspond to further fragmentation of the ejected monomer after expulsion from the oligomeric protein. In this case however, covalent cleavage of the protein appears to be a competitive process to noncovalent subunit ejection. This is evident from the observation of complementary fragment ions between 5300 and $6600 \mathrm{~m} / \mathrm{z}$ that correspond to [pentamer- $\left.\mathrm{y}_{40}\right]^{22+}$, [pentamer$\left.\left(2 \mathrm{y}_{40}\right)\right]^{19+}$, and [pentamer- $\left.\mathrm{y}_{30}\right]^{23+}$. This process, summarized in Scheme 2, is an unusual example of backbone fragmentation from oligomeric proteins by CID, while preserving some of the noncovalent interactions between subunits as well as the covalently bound saccharide.

Table 1 lists each of the complementary covalent fragment ions observed by CID and the site of backbone cleavage. Each covalent bond cleavage occurs at a site known to be enhanced in peptides with a mobile or partially mobile proton, such as $\mathrm{N}$-terminal to proline or glycine [66]. Equally noteworthy is that SID at 1750 $\mathrm{eV}$ reveals dissociation of the pentamer into monomers and dimers, but shows no evidence of covalent backbone fragmentation. This may signify that covalent

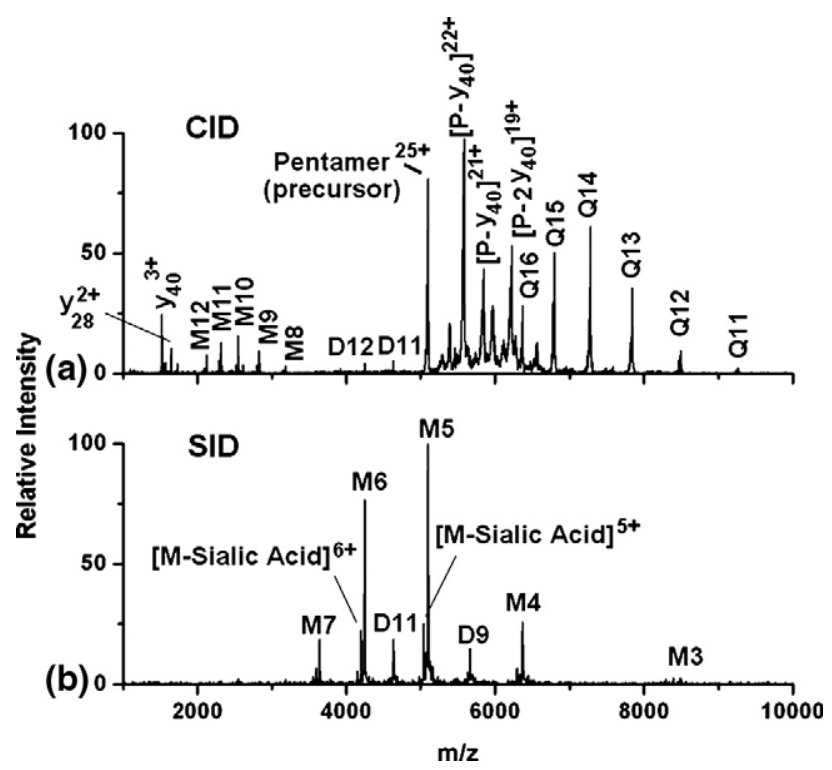

Figure 5. MS/MS of the serum amyloid $\mathrm{P}$ component (SAP) pentamer. (a) CID of the $25+$ pentamer at $2500 \mathrm{eV}$ produces monomer and tetramer fragments, with the monomer retaining approximately $40 \%$ of the charge. (b) SID of the same precursor ion at $1750 \mathrm{eV}$ produces monomers and dimers with $1 / 5$ and $2 / 5$ of the precursor charge, respectively.

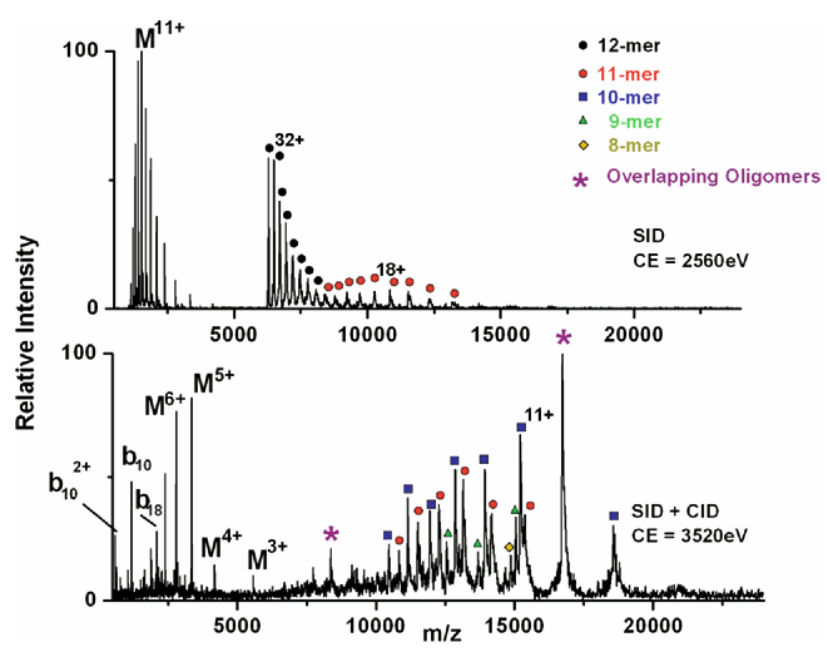

Figure 6. MS/MS of the $32+$ dodecamer of TaHSP16.9. SID at a collision energy of $2560 \mathrm{eV}$ (top) produces several charge-stripped dodecameric ions along with monomer and undecamer fragments. SID of TaHSP16.9 at a collision energy of $3520 \mathrm{eV}$ with Ar gas also present in the collision cell (bottom) produces more extensive fragmentation to give octamers through undecamers, in addition to covalent fragmentation of the monomer population along the protein backbone.

cleavage directly from the pentamer is facilitated by charge transfer to the unfolding subunit during CID. The charge-enriched environment created as a SAP subunit unfolds during CID leads to a situation in which the monomer contains more protons $(\sim 10$ judging from the charge state of the dissociating monomer) than Arg residues (9), the most basic, and thus most tightly proton-sequestering residue. Selective cleavages N-terminal to Pro have been extensively documented in the peptide fragmentation literature [66-69], especially in cases where the number of protons exceeds the number of Arg, and are free to initiate charge-directed cleavage of the protein backbone [66]. For the SAP pentamer, the fact that this cleavage appears to compete with removal of a noncovalent subunit may be useful in

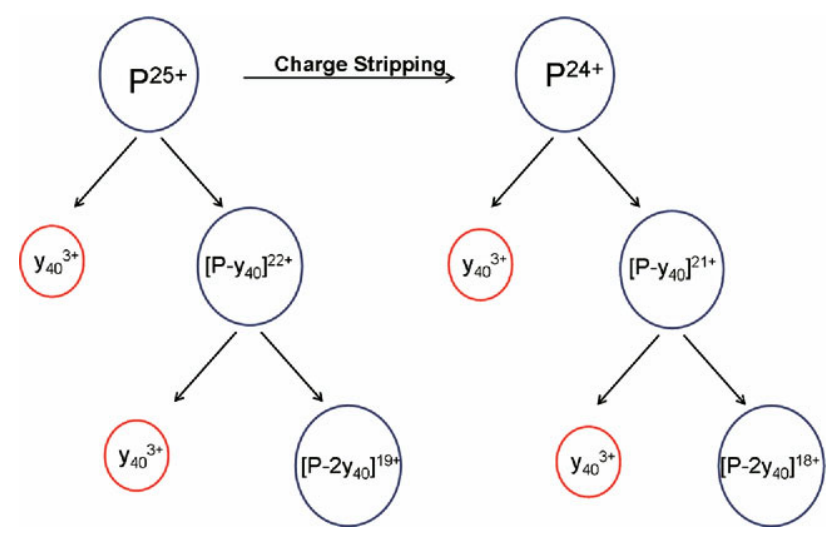

Scheme 2. Representation of covalent backbone fragmentation directly from CID of the pentamer SAP. The $y_{40}{ }^{3+}$ ions are complemented by ions corresponding to the loss of $\mathrm{y}_{40}{ }^{3+}$ from the $25+$ pentamer, and are in competition with the ejection of an entire noncovalently bound subunit. 
Table 1. Fragment ions observed in the CID spectrum of SAP corresponding to covalent backbone fragmentation directly from SAP pentamer $^{\mathrm{a}}$

\begin{tabular}{|c|c|c|c|c|c|c|c|}
\hline $\begin{array}{l}\text { Fragment ions observed } \\
\text { by CID }\end{array}$ & $\begin{array}{c}\text { Charge } \\
\text { state }\end{array}$ & $\begin{array}{c}\text { Theoretical } \\
\mathrm{m} / \mathrm{z}\end{array}$ & $\begin{array}{l}\text { Measured } \\
\mathrm{m} / \mathrm{z}\end{array}$ & $\Delta m / z$ & $\begin{array}{l}\text { Cleavage: } \mathrm{N} \text {-term./ } \\
\text { C-term residue }\end{array}$ & $\begin{array}{c}\text { Complementary } \\
\text { fragment }\end{array}$ & $\begin{array}{l}\text { Complementary } \\
\text { charge state }\end{array}$ \\
\hline Pentamer (precursor) & $25+$ & 5093.48 & 5095.95 & -2.47 & - & - & - \\
\hline Pentamer & $24+$ & 5305.67 & 5308.14 & -2.47 & - & - & - \\
\hline $\mathrm{y}_{40}-\mathrm{NH}_{3}$ & $3+$ & 1517.45 & 1517.38 & 0.07 & Leu/Pro & - & - \\
\hline $\mathrm{y}_{40}$ & $3+$ & 1523.13 & 1523.40 & -0.27 & Leu/Pro & Pentamer- $\mathrm{y}_{40}$ & $22+$ \\
\hline $\mathrm{Y}_{28}$ & $2+$ & 1648.49 & 1648.46 & 0.03 & Thr/Pro & - & - \\
\hline $\mathrm{y}_{30}$ & $2+$ & 1727.56 & 1727.73 & -0.17 & Glu/Gly & Pentamer- $y_{30}$ & $23+$ \\
\hline Pentamer- $\mathrm{y}_{40}$ & $22+$ & 5580.35 & 5582.71 & -2.36 & Leu/Pro & $y_{40}$ & $3+$ \\
\hline Pentamer- $\mathrm{y}_{40}$ & $21+$ & 5846.03 & 5848.62 & -2.59 & Leu/Pro & $\mathrm{y}_{40}$ & $3+$ \\
\hline Pentamer- $\left(2 \mathrm{y}_{40}\right)$ & $19+$ & 6220.96 & 6223.03 & -2.07 & Leu/Pro & $2 y_{40}$ & $3+$ \\
\hline Pentamer- $\left(2 \mathrm{y}_{40}\right)$ & $18+$ & 6566.52 & 6568.90 & -2.38 & Leu/Pro & $2 y_{40}$ & $3+$ \\
\hline Pentamer- $y_{30}$ & $23+$ & 5386.17 & 5387.14 & -0.97 & Glu/Gly & $\mathrm{y}_{30}$ & $2+$ \\
\hline
\end{tabular}

${ }^{a} \Delta m / z$ corresponds to the difference between the theoretical $m / z$ as determined from the amino acid sequence and the experimentally measured $m / z$. The measured values for the intact pentamer and the fragment ions for which at least a portion of all five subunits are still bound (i.e., Pentamer-covalents) are heavy by about $2-2.5 \mathrm{~m} / \mathrm{z}$ attributed to the presence of solvent adducts.

elucidating mechanistic aspects of the unfolding and charge-transfer process that occurs during CID, although it is not currently understood why this is observed for CID of SAP, but not other oligomeric protein systems.

Table 2 shows the average number of charges retained by monomers produced by CID and SID from several mass-selected oligomers [27]. The average charge state is higher in all cases for CID than for SID, consistent with more unfolding, allowing higher charging by CID. The monomer ejected during CID takes away close to $50 \%$ of the charge from the original precursor in every case [15]. The percentage of the precursor ion charge retained by SID-generated monomers, however, approaches the statistical mass percentage of each subunit within the intact complex. For example, monomers produced from pentameric C-reactive protein constitute $20 \%$ of the overall mass of the intact complex, and SID yields monomers that retain $21 \%$ of the charge. Similarly, SID of tetrameric transthyretin (TTR) yields monomers that retain $29 \%$ of the charge compared to $25 \%$ composition by mass. It is possible that the minor discrepancies between the charge and mass percentage of SID-generated monomers is a result of the presence of low-abundance charge asymmet- ric products in the SID spectra of each complex. Energyresolved studies of TTR have shown that at low collision energies, the SID products are similar in mass and charge partitioning to those produced by CID [27]. As collision energy increases, the monomer distribution becomes more charge symmetric with respect to mass, although some of the asymmetric pathways are still observed to a minor extent. Consequently, the rapid deposition of higher internal energy may serve to better access dissociation pathways that lead to charge symmetric dissociation. To date, only scarce data are available regarding the conformation of SID-generated product ions, but the evidence of charge-symmetric monomers implies a large degree of conformational similarity among the dissociating subunits. It is presumed here that the monomers remain mostly folded upon dissociating from one another, leading to their enhanced charge symmetry. It is not clear whether unfolding may occur after dissociation from the intact complex, but the dissociating subunits would not be capable of charge transfer after separating from one another. Clearly, additional work, such as the combination of SID with ion mobility, is needed to test the validity of this presumption.

Table 2. Charge state statistics for monomer product ions ejected during collision- and surface-induced dissociation of the listed charge state of the precursor protein complex ${ }^{\mathrm{a}}$

\begin{tabular}{|c|c|c|c|c|c|c|c|c|c|c|}
\hline & \multicolumn{2}{|c|}{$\begin{array}{l}\text { Transthyretin } \\
15+\text { tetramer } \\
\end{array}$} & \multicolumn{2}{|c|}{$\begin{array}{c}\text { Concanavalin } \\
\text { A } 22+ \\
\text { tetramer } \\
\end{array}$} & \multicolumn{2}{|c|}{$\begin{array}{c}\text { Hemoglobin } \\
(\alpha \text {-subunit) } \\
15+\text { tetramer } \\
\end{array}$} & \multicolumn{2}{|c|}{$\begin{array}{c}\text { Hemoglobin } \\
(\beta \text {-subunit) } \\
17+\text { tetramer } \\
\end{array}$} & \multicolumn{2}{|c|}{$\begin{array}{l}\text { C-reactive } \\
\text { protein }\end{array}$} \\
\hline & CID & SID & CID & SID & CID & SID & CID & SID & CID & SID \\
\hline Average charge state & 7.7 & 4.4 & 12.5 & 6.4 & 8.5 & 5.3 & 9.0 & 5.6 & 11.5 & 5.5 \\
\hline $\begin{array}{l}\text { Expected charge state } \\
\text { (based on mass) }\end{array}$ & \multicolumn{2}{|c|}{3.8} & \multicolumn{2}{|c|}{5.5} & \multicolumn{2}{|c|}{4.0} & \multicolumn{2}{|c|}{4.2} & \multicolumn{2}{|c|}{5.2} \\
\hline$\%$ Charge of precursor & $51 \%$ & $29 \%$ & $57 \%$ & $29 \%$ & $50 \%$ & $31 \%$ & $53 \%$ & $33 \%$ & $44 \%$ & $21 \%$ \\
\hline$\%$ Mass of precursor & \multicolumn{2}{|c|}{$25 \%$} & \multicolumn{2}{|c|}{$25 \%$} & \multicolumn{2}{|c|}{$24 \%$} & \multicolumn{2}{|c|}{$25 \%$} & \multicolumn{2}{|c|}{$20 \%$} \\
\hline
\end{tabular}

an all cases, the average charge state of the ejected monomers is lower for SID than that for CID and is within a few percent of the \% charge that would be expected if the charge is distributed evenly across the subunits (e.g., for a homotetramer, the monomer is $25 \%$ of the total mass and could be expected to carry away $25 \%$ of the total charge). 
Table 3. Covalent fragments identified from the SID spectrum of TaHSP16.9 shown in the bottom panel of Figure 6

\begin{tabular}{ccccc}
\hline Covalent Fragment ion & Theoretical $m / z$ & Measured $m / z$ & $\Delta m / z$ & Cleavage: N-terminal/C-terminal residue \\
\hline \hline $\mathrm{b}_{10^{2+}}{ }^{2+}$ & 587.8200 & 587.8406 & -0.0206 & Asp/Pro \\
$\mathrm{b}_{5}{ }^{+}$ & 612.3940 & 612.4098 & -0.0158 & Arg/Ser \\
$\mathrm{y}_{7}{ }^{+}$ & 716.4301 & 716.5059 & -0.0758 & Lys/Ala \\
$\mathrm{y}_{10}{ }^{+}$ & 1041.5952 & 1041.6503 & -0.0551 & Lys/Pro \\
$\mathrm{b}_{18}{ }^{+}$ & 1045.5263 & 1045.5457 & -0.0194 & Asp/Pro \\
{$\left[\mathrm{b}_{10^{-}} \mathrm{H}_{2} \mathrm{O}\right]^{+}$} & 1156.6222 & 1156.6248 & -0.0026 & Asp/Pro \\
$\mathrm{y}_{11}{ }^{+}$ & 1169.6888 & 1169.6998 & -0.0110 & Lys/Lys \\
$\mathrm{b}_{10}{ }^{+}$ & 1174.6327 & 1174.6403 & -0.0076 & Asp/Pro \\
$\mathrm{b}_{14}{ }^{+}$ & 1604.8180 & 1604.7990 & -0.0190 & Asp/Leu \\
$\mathrm{b}_{18}{ }^{+}$ & 2090.0454 & 2090.0776 & -0.0322 & Asp/Pro \\
\hline
\end{tabular}

We have previously shown that SID can be used to fragment protein complexes over $200 \mathrm{kD}[28,29]$. Surfaceinduced dissociation of the TaHSP16.9 dodecamer with 32 charges is shown in the top panel of Figure 6, for comparison with the CID spectrum from Figure 1. SID of the dodecamer at a collision energy of $2560 \mathrm{eV}$ looks similar to the CID spectrum at $3520 \mathrm{eV}$, with respect to the mass of the product ions. In both cases, the dodecamer fragments into monomers and undecamers, with relatively asymmetric partitioning of the charge. One notable difference is a higher extent of charge-stripped dodecamer following surface collision. Charge stripping has been attributed to the loss of positively charged solvent adducts, such as ammonium, from the intact complex, and in the case of SID might also involve charge transfer to the surface [70]. Proton transfer from the projectile ion to the surface has been observed in some soft-landing experiments, including those conducted on fluorinated self-assembled monolayers as used here [71, 72]. Although the CID and SID product ions are similar in these cases, the SID of smaller complexes has been observed to be highly dependent on collision energy, as stated earlier. For this reason, higher SID collision energies were explored to see whether fragmentation could be achieved without significant monomer unfolding. The bottom panel of Figure 6 shows SID at a collision energy of $3520 \mathrm{eV}$. In this case, argon was also used in the gas cell following the surface collision to assist in ion transmission and provide further activation. The high $m / z$ region above 10,000 shows products ranging from 8-mers to 11-mers, whereas much of the monomer population in the low $\mathrm{m} / \mathrm{z}$ region has further dissociated to give covalent fragmentation along the protein backbone. As in the case of SAP, the covalent fragments are predominantly low charge $b$ - and y-ions, dominated by cleavage at select sites, such as N-terminal to Pro-11 and Pro-19. In contrast to the SAP CID spectrum however, the covalent fragments observed in Figure 6 are secondary fragments of the ejected monomer, as evident from the lack of complementary fragments that remain noncovalently bound to other subunits. Table 3 provides a list of the covalent fragments identified from the bottom spectrum in Figure 6. Benesch et al. have shown that at the highest CID collision energies available in a Q-ToF
2 instrument, up to two monomers can be sequentially ejected from the intact TaHSP16.9 dodecamer (i.e., the 12-mer dissociates to 11-mer, which in turn further fragments to 10-mer) [10]. Although 10-mers dominate the high $m / z$ end of the SID spectrum, 11-mers, 9-mers, and 8-mers are also observed. The peaks marked with an asterisk at $m / z 16,274$ and 8362 correspond to overlapping oligomers with one and two charges per subunit, respectively (i.e., where the $11+$ undecamer, $10+$ decamer, etc. would overlap in mass-to-charge ratio). Whether the 8-, 9-, and 10-mers are the products of sequential monomer stripping, or form directly from the 12-mer, is still under investigation, but in either case, colliding the intact complex into a surface before sending it through the gas-filled collision cell provides more extensive fragmentation of the complex than CID alone.

Another important observation in comparison of SID and CID results is the fact that lower kinetic energies can be used for SID, with its more massive target, than for CID where the target is substantially lower in mass. This is illustrated by plots of fragmentation efficiency versus collision energy in Figure 7 for CID and SID of TaHSP16.9. When colliding TaHSP16.9 into a surface, the point corresponding to $50 \%$ fragmentation of the dodecamer occurs at a laboratory collision energy that

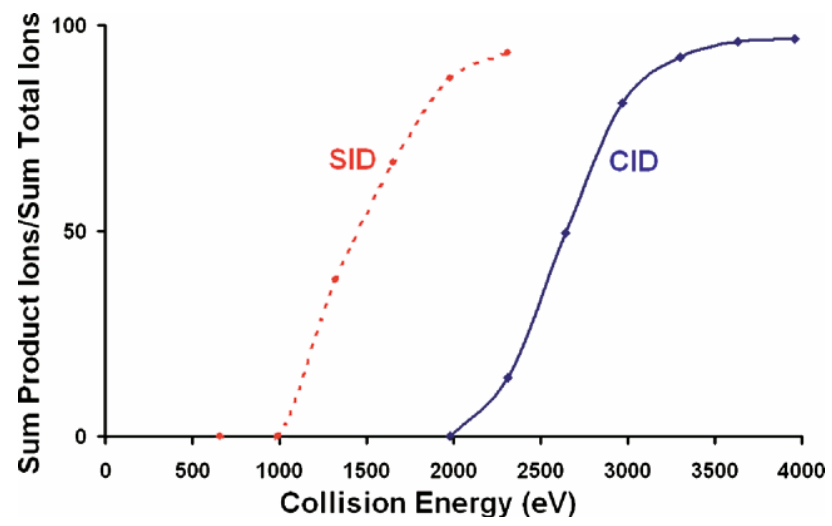

Figure 7. Fragmentation efficiency curves for dodecamers of TaHSP16.9 dissociated via SID or CID. Much lower laboratory collision energy is needed to fragment TaHSP16.9 when a surface is used as the collision partner. 


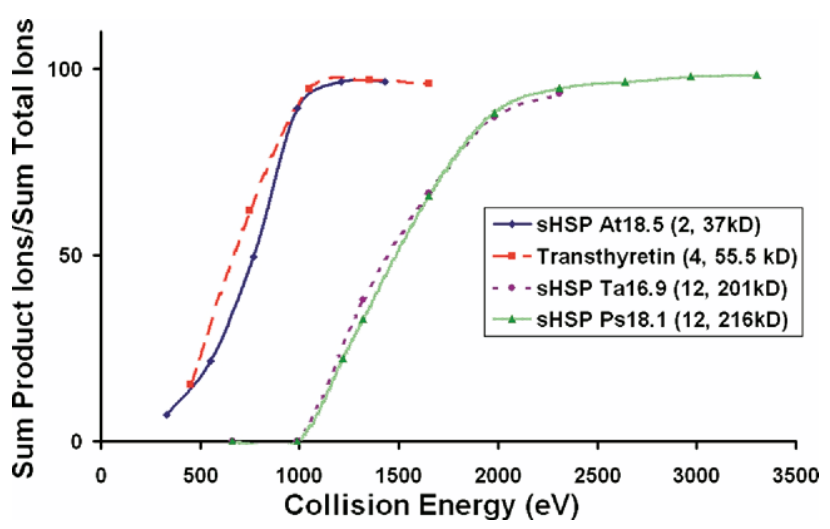

Figure 8. Fragmentation efficiency curves for four different protein-protein complexes. The laboratory collision energy shifts with the mass of the complex, indicating statistical fragmentation behavior. The inset legend lists each complex, the number of subunits, and the molecular weight.

is more than $1000 \mathrm{eV}$ lower than when colliding the protein into argon, despite the fact that the complex undergoes several thousand collisions via CID. This clearly demonstrates the potential for more extensive fragmentation by SID than $b$ CID.

An important question that arises in surface-induced dissociation studies of large complexes is whether the fragmentation conforms to expected kinetic theory of mass spectrometry, where it is expected that fragmentation rates will increase when kinetic energy of collision is increased and that greater amounts of internal energy will be needed to fragment larger precursor ions $[17,18,45]$. Both expectations have been shown to be met by SID of large noncovalent protein complexes, as illustrated in Figure 8, which shows fragmentation efficiency curves for an sHSP dimer (AtHSP18.5, 37 $\mathrm{kDa})$, transthyretin tetramer $(\sim 55.5 \mathrm{kDa})$, and two sHSP dodecamers at about $201 \mathrm{kDa}(\mathrm{TaHSP} 16.9)$ and about $216 \mathrm{kDa}$ (PsHSP18.1). The amount of fragmentation varies with collision energy and the more massive complexes require higher collision energies for onset of fragmentation.

\section{Conclusions}

Surface-induced dissociation shows much more extensive dissociation of protein complexes and inorganic CsI clusters than is observed by CID. In the case of CsI clusters, CID generates consecutive neutral losses of CsI moieties, whereas SID provides access not only to this pathway, but also to a higher energy charge fission process. This process results in a splitting of the CsI clusters in such a way that favors the formation of symmetrically stable magic number cluster products.

Upon SID of protein-protein complexes, monomers are ejected from oligomers with a charge-state distribution that is much closer than that of CID to the statistical prediction made by taking the total charge and dividing by the oligomer number. Energies required to promote dissociation on the timescale of the instrument have been found to be lower for SID than for CID and the extent of dissociation increases with an increase in collision energy. Thus far, most of the SID data have involved homooligomers. Clearly, more work is needed on heterogeneous protein complexes where SID has the potential to provide substructure information. It is also desirable to combine the SID technique with ion mobility so that ions can be shape-selected before surface collision or so that shape can be monitored after surface collision. SID has great potential to contribute to structural biology studies and studies of other large macromolecular complexes.

\section{Acknowledgments}

The authors gratefully acknowledge Dr. Elizabeth Vierling, Eman Basha, and Nomalie Jaya for providing samples of small heat shock proteins and Dr. Richard Beardsley for helpful discussions. We also acknowledge financial support from NSF DBI Grant CHE 024447 for development of the QToF instrument and NIH Grant 5R01 GM-051387 for support of experiments on fragmentation. CMJ thanks Pfizer for a Graduate Research Fellowship in Analytical Chemistry and AEB thanks Science Foundation Arizona.

\section{References}

1. Damoc, E.; Fraser, C. S.; Zhou, M.; Videler, H.; Mayeur, G. L.; Hershey, J. W. B.; Doudna, J. A.; Robinson, C. V.; Leary, J. A. Structural Characterization of the Human Eukaryotic Initiation Factor 3 Protein Complex by Mass Spectrometry. Mol. Cell. Proteomics 2007, 6, 1135-1146.

2. Aquilina, J. A.; Benesch, J. L. P.; Bateman, O. A.; Slingsby, C.; Robinson, C. V. Polydispersity of a Mammalian Chaperone: Mass Spectrometry Reveals the Population of Oligomers in alpha B-Crystallin. Proc. Natl. Acad. Sci. U.S.A. 2003, 100, 10611-10616.

3. Boskovic, J.; Coloma, J.; Aparicio, T.; Zhou, M.; Robinson, C. V.; Mendez, J.; Montoya, G. Molecular Architecture of the Human GINS Complex. EMBO Rep. 2007, 8, 678-684.

4. Taverner, T.; Hernández, H.; Sharon, M.; Ruotolo, B. T.; MatakVinković, D.; Devos, D.; Russell, R. B.; Robinson, C. V. Subunit Architecture of Intact Protein Complexes from Mass Spectrometry and Homology Modeling. Acc. Chem. Res. 2008, March 4 [Epub ahead of print].

5. Xie, Y. M.; Zhang, J.; Yin, S.; Loo, J. A. Top-Down ESI-ECD-FT-ICR Mass Spectrometry Localizes Noncovalent Protein-Ligand Binding Sites. J. Am. Chem. Soc. 2006, 128, 14432-14433.

6. Bernstein, S. L.; Wyttenbach, T.; Baumketner, A.; Shea, J. E.; Bitan, G.; Teplow, D. B.; Bowers, M. T. Amyloid Beta-Protein: Monomer Structure and Early Aggregation States of A beta 42 and its Pro(19) Alloform. J. Am. Chem. Soc. 2005, 127, 2075-2084.

7. van den Heuvel, R. H. H.; Gato, S.; Versluis, C.; Gerbaux, P.; Kleanthous, C.; Heck, A. J. R. Real-Time Monitoring of Enzymatic DNA Hydrolysis by Electrospray Ionization Mass Spectrometry. Nucleic Acids Res. 2005, 33, e96.

8. Sobott, F.; Benesch, J. L. P.; Vierling, E.; Robinson, C. V. Subunit Exchange of Multimeric Protein Complexes: Real-Time Monitoring of Subunit Exchange between Small Heat Shock Proteins by Using Electrospray Mass Spectrometry. J. Biol. Chem. 2002, 277, 38921-38929.

9. van Duijn, E.; Simmons, D. A.; van den Heuvel, R. H. H.; Bakkes, P. J.; van Heerikhuizen, H.; Heeren, R. M. A.; Robinson, C. V.; van der Vies, S. M.; Heck, A. J. R. Tandem Mass Spectrometry of Intact GroELSubstrate Complexes Reveals Substrate-Specific Conformational Changes in the trans Ring. J. Am. Chem. Soc. 2006, 128, 4694-4702.

10. Benesch, J. L. P.; Aquilina, J. A.; Ruotolo, B. T.; Sobott, F.; Robinson, C. V. Tandem Mass Spectrometry Reveals the Quaternary Organization of Macromolecular Assemblies. Chem. Biol. 2006, 13, 597-605.

11. Benesch, J. L. P.; Sobott, F.; Robinson, C. V. Thermal Dissociation of Multimeric Protein Complexes by Using Nanoelectrospray Mass Spectrometry. Anal. Chem. 2003, 75, 2208-2214.

12. Felitsyn, N.; Kitova, E. N.; Klassen, J. S. Thermal Decomposition of a Gaseous Multiprotein Complex Studied by Blackbody Infrared Radiative Dissociation. Investigating the Origin of the Asymmetric Dissociation Behavior. Anal. Chem. 2001, 73, 4647-4661.

13. Jurchen, J. C.; Williams, E. R. Origin of Asymmetric Charge Partitioning in the Dissociation of Gas-Phase Protein Homodimers. J. Am. Chem. Soc. 2003, 125, 2817-2826.

14. Ruotolo, B. T.; Hyung, S. J.; Robinson, P. M.; Giles, K.; Bateman, R. H.; Robinson, C. V. Ion Mobility-Mass Spectrometry Reveals Long-Lived, 
Unfolded Intermediates in the Dissociation of Protein Complexes. Angew. Chem. Int. Ed. 2007, 46, 8001-8004.

15. Wanasundara, S. N.; Thachuk, M. Theoretical Investigations of the Dissociation of Charged Protein Complexes in the Gas Phase. J. Am. Soc. Mass Spectrom. 2007, 18, 2242-2253.

16. van Montfort, R. L. M.; Basha, E.; Friedrich, K. L.; Slingsby, C.; Vierling E. Crystal Structure and Assembly of a Eukaryotic Small Heat Shock Protein. Nat. Struct. Biol. 2001, 8, 1025-1030.

17. McLuckey, S. A. Principles of Collisional Activation in Analytical Mass-Spectrometry. J. Am. Soc. Mass Spectrom. 1992, 3, 599-614.

18. Shukla, A. K.; Futrell, J. H. Tandem Mass Spectrometry: Dissociation of Ions by Collisional Activation. I. Mass Spectrom. 2000, 35, 1069-1090.

19. Lorenzen, K.; Versluis, C.; van Duijn, E.; van den Heuvel, R. H. H.; Heck, A. J. R. Optimizing Macromolecular Tandem Mass Spectrometry of Large Non-Covalent Complexes Using Heavy Collision Gases. Int. J. Mass Spectrom. 2007, 268, 198-206.

20. Geels, R. B. J. van der Vies, S. M. Heck, A. J. R.; Heeren, R. M. A. Electron Capture Dissociation as Structural Probe for Noncovalent Gas-Phase Protein Assemblies. Anal. Chem. 2006, 78, 7191-7196.

21. Laskin, J.; Futrell, J. H. Energy Transfer in Collisions of Peptide Ions with Surfaces. J. Chem. Phys. 2003, 119, 341-3420.

22. Smith, D. L.; Wysocki, V. H.; Colorado, R., Jr.; Shmakova, O. E.; Graupe, M.; Lee, R. T. Low-Energy Ion-Surface Collisions Characterize Alkyland Fluoroalkyl-Terminated Self-Assembled Monolayers on Gold. Langmuir 2002, 18, 3895-3902.

23. Vekey, K.; Somogyi, A.; Wysocki, V. H. Internal Energy Distribution of Benzene Molecular Ions in Surface-Induced Dissociation. J. Mass Spectrom. 1995, 30, 212-217.

24. Vekey, K.; Somogyi, A.; Wysocki, V. H. Average Activation Energies of Low-Energy Fragmentation Processes of Protonated Peptides Determined by a New Approach. Rapid Commun. Mass Spectrom. 1996, 10, 911-918.

25. Lim, H. J.; Schultz, D. G.; Yu, C. W.; Hanley, L. Relative Dissociation Energies of Protonated Peptides by Electrospray Ionization SurfaceInduced Dissociation. Anal. Chem. 1999, 71, 2307-2317.

26. Laskin, J.; Futrell, J. H. Collisional Activation of Peptide Ions in FT-ICR Mass Spectrometry. Mass Spectrom. Rev. 2003, 22, 158-181.

27. Beardsley, R. L.; Jones, C. M.; Galhena, A. S.; Wysocki, V. H. Investigations of the Surface-Induced Dissociation of Non-Covalent Protein Complexes in the Gas Phase. J. Am. Chem. Soc. In Preparation.

28. Galhena, A. S.; Dagan, S.; Jones, C. M.; Beardsley, R. L.; Wysocki, V. H. Surface-Induced Dissociation of Peptides and Protein Complexes in a Quadrupole/Time-of-Flight Mass Spectrometer. Anal. Chem. 2008, 80, 1425-1436.

29. Wysocki, V. H.; Joyce, K. E.; Jones, C. M.; Beardsley, R. L. SurfaceInduced Dissociation of Small Molecules, Peptides, and Non-Covalent Protein Complexes. J. Am. Soc. Mass Spectrom. 2008, 19, 190-208.

30. Jones, C. M.; Beardsley, R. L.; Galhena, A. S.; Dagan, S.; Cheng, G. L.; Wysocki, V. H. Symmetrical Gas-Phase Dissociation of Noncovalent Protein Complexes via Surface Collisions. J. Am. Chem. Soc. 2006, 128, 15044-15045.

31. Stace, A. J. Metal Ion Solvation in the Gas Phase: The Quest for Higher Oxidation States. J. Phys. Chem. A 2002, 106, 7993-8005.

32. Mark, T. D. Cluster Ions-Production, Detection and Stability. Int. J. Mass Spectrom. Ion Process. 1987, 79, 1-59.

33. Castleman, A. W. Reactions and Properties of Clusters. Int. I. Mass Spectrom. Ion Process. 1992, 118, 167-189.

34. Busch, K. L.; Cooks, R. G. Mass-Spectrometry of Large, Fragile, and Involatile Molecules. Science 1982, 218, 247-254.

35. Barlak, T. M.; Wyatt, J. R.; Colton, R. J.; Decorpo, J. J.; Campana, J. E. Secondary Ion Mass-Spectrometry of Metal-Halides. 2. Evidence for Structure in Alkali Iodide Clusters. J. Am. Chem. Soc. 1982, 104, 12121215.

36. Baldwin, M. A.; Proctor, C. J.; Amster, I. J.; Mclafferty, F. W. The Behavior of Cesium Iodide Cluster Ions Produced by Fast-Atom Bombardment. Int. J. Mass Spectrom. Ion Process. 1983, 54, 97-107.

37. Campana, J. E.; Green, B. N. Unicluster Dissociation of Large Alkali Iodide Cluster Ions. J. Am. Chem. Soc. 1984, 106, 531-535.

38. Honea, E. C.; Homer, M. L.; Whetten, R. L. Electron-Binding and Stability of Excess-Electron Alkali-Halide Clusters-Localization and Surface-States. Phys. Rev. B 1993, 47, 7480-7493.

39. Morgan, T. G.; Rabrenovic, M.; Harris, F. M.; Beynon, J. H. Investigation of the Relative Stability of Positive Alkali-Halide Cluster Ions Generated by Fast Atom Bombardment. Org. Mass Spectrom. 1984, 19, 315-320.

40. Drewello, T.; Herzschuh, R.; Stach, J. Direct Fission Versus Sequential Evaporation Mechanism of Sputtered Cesium Iodide Cluster Ions. Z. Phys. D At. Mol. Clusters 1993, 28, 339-343.

41. Derrick, P. J.; Colburn, A. W.; Sheil, M. M.; Uggerud, E. Collisional Excitation and Fragmentation of Alkali-Metal Halide Cluster Ions. J. Chem. Soc. Faraday Trans. 1990, 86, 2533-2535.

42. Vekey, K.; Czira, G. Large Translational Energy-Loss and Scattering in Collision-Induced Dissociation Processes. Org. Mass Spectrom. 1993, 28, $546-551$.

43. Vekey, K.; Ludanyi, K. Translational Energy-Losses of Lif Cluster Ions. Org. Mass Spectrom. 1994, 29, 615-618.

44. Sobott, F.; Hernández, H.; McCammon, M. G.; Tito, M. A.; Robinson, C. V. A Tandem Mass Spectrometer for Improved Transmission and Analysis of Large Macromolecular Assemblies. Anal. Chem. 2002, 74, 1402-1407.
45. Griffin, L. L.; McAdoo, D. J. The Effect of Ion Size on Rate of Dissociation-RRKM Calculations on Model Large Polypeptide Ions. J. Am. Soc. Mass Spectrom. 1993, 4, 11-15.

46. Callahan, J. H.; Somogyi, A.; Wysocki, V. H. Collisions of C-60(+.) and $\mathrm{C}-60(2+)$ at Fluorinated and Non-Fluorinated Self-Assembled Monolayer Films. Rapid Commun. Mass Spectrom. 1993, 7, 693-699.

47. Kane, T. E.; Somogyi, A.; Wysocki, V. H. Reactive Ion-Surface Collisions-Application of Ionized Acetone-D(6), DMSO-D(6) and PyridineD(5) as Probes for the Characterization of Self-Assembled Monolayer Films on Gold. Org. Mass Spectrom. 1993, 28, 1665-1673.

48. Mckay, A. R.; Ruotolo, B. T.; Ilag, L. L.; Robinson, C. V. Mass Measurements of Increased Accuracy Resolve Heterogeneous Populations of Intact Ribosomes. J. Am. Chem. Soc. 2006, 128, 11433-11442.

49. Ilag, L. L.; Videler, H.; McKay, A. R.; Sobott, F.; Fucini, P.; Nierhaus, K. H.; Robinson, C. V. Heptameric (L12)(6)/L10 Rather Than Canonical Pentameric Complexes Are Found by Tandem MS of Intact Ribosomes from Thermophilic Bacteria. Proc. Natl. Acad. Sci. U.S.A. 2005, 102, 8192-8197.

50. Rostom, A. A. Fucini, P. Benjamin, D. R. Juenemann, R - Nierhaus, K. H.; Hartl, F. U.; Dobson, C. M. Robinson, C. V. Detection and Selective Dissociation of Intact Ribosomes in a Mass Spectrometer. Proc. Natl. Acad. Sci. U.S.A. 2000, 97, 5185-5190.

51. Herzschuh, R.; Drewello, T. The Fragmentation Dynamics of Small $\mathrm{Cs}(\mathrm{CsI})(\mathrm{n})(+)$ Cluster Ions under Low-Energy Multiple Collision Conditions. Int. J. Mass Spectrom. 2004, 233, 355-359.

52. Martin, T. P. Structure and Vibrational Frequencies of Ionic Clusters J. Chem. Phys. 1978, 69, 2036-2042.

53. Martin, T. P. The Structure of Ionic Clusters-Thermodynamic Functions, Energy Surfaces, and Sims. J. Chem. Phys. 1980, 72, 3506-3510.

54. Martin, T. P. Stability of Doubly Charged Alkali-Halide Clusters. J. Chem. Phys. 1982, 76, 5467-5469.

55. Zhang, D. X.; Cooks, R. G. Doubly Charged Cluster Ions $[(\mathrm{NaCl})(\mathrm{m})$ $(\mathrm{Na})(2)](2+)$ : Magic Numbers, Dissociation, and Structure. Int. J. Mass Spectrom. 2000, 196, 667-684

56. Echt, O.; Flotte, A. R.; Knapp, M.; Sattler, K.; Recknagel, E. Magic Numbers in Mass-Spectra of Xe, C2f4cl2 and Sf6 Clusters. Phys. Chem. Chem. Phys. 1982, 86, 860-865.

57. Echt, O.; Sattler, K.; Recknagel, E. Magic Numbers for Sphere Packings-Experimental-Verification in Free Xenon Clusters. Phys. Rev. Lett. 1981, 47, 1121-1124.

58. Barlak, T. M.; Campana, J. E.; Colton, R. J.; Decorpo, J. J.; Wyatt, J. R. Secondary Ion Mass-Spectrometry of Metal-Halides. 1. Stability of Alkali Iodide Clusters. J. Phys. Chem. 1981, 85, 3840-3844.

59. Muhlbach, J.; Sattler, K.; Pfau, P.; Recknagel, E. Evidence for Magic Numbers of Free Lead-Clusters. Phys. Lett. A 1982, 87, 415-417.

60. Campana, J. E.; Colton, R. J.; Wyatt, J. R.; Bateman, R. H.; Green, B. N. Ultrahigh Mass-Spectrometry. Appl. Spectrosc. 1984, 38, 430-432.

61. Stjohn, P. M.; Beck, R. D.; Whetten, R. L. Fragmentation and Reaction Processes in Cluster-Surface Collisions. Z. Phys. D At. Mol. Clusters 1993, $26,226-228$.

62. Beck, R. D.; Stjohn, P.; Homer, M. L.; Whetten, R. L. Impact-Induced Cleaving and Melting of Alkali-Halide Nanocrystals. Science 1991, 253, 879-883.

63. Beck, R. D.; John, P. S. Homer, M. L.; Yeretzian, C.; Whetten, R. L. Scattering of Mass-Selected Cluster Beams from Solid-Surfaces. Am. Chem. Soc. Abstr. 1992, 204, 264-PHYS.

64. Jurchen, J. C.; Garcia, D. E.; Williams, E. R. Further Studies on the Origins of Asymmetric Charge Partitioning in Protein Homodimers. J. Am. Soc. Mass Spectrom. 2004, 15, 1408-1415.

65. Versluis, C.; van der Staaij, A.; Stokvis, E.; Heck, A. J. R.; de Craene, B. Metastable Ion Formation and Disparate Charge Separation in the Gas-Phase Dissection of Protein Assemblies Studied by Orthogona Time-of-Flight Mass Spectrometry. J. Am. Soc. Mass Spectrom. 2001, 12 329-336.

66. Huang, Y. Y.; Triscari, J. M.; Tseng, G. C.; Pasa-Tolic, L.; Lipton, M. S.; Smith, R. D.; Wysocki, V. H. Statistical Characterization of the Charge State and Residue Dependence of Low-Energy CID Peptide Dissociation Patterns. Anal. Chem. 2005, 77, 5800-5813.

67. Wysocki, V. H.; Tsaprailis, G.; Smith, L. L.; Breci, L. A. Mobile and Localized Protons: A Framework for Understanding Peptide Dissociation. J. Mass Spectrom. 2000, 35, 1399-1406.

68. Breci, L. A.; Tabb, D. L.; Yates, J. R. III; Wysocki, V. H. Cleavage N-Terminal to Proline: Analysis of a Database of Peptide Tandem Mass Spectra. Anal. Chem. 2003, 75, 1963-1971.

69. Leymarie, N; Berg, E. A.; McComb, M. E.; O'Connor, P. B.; Grogan, J. Oppenheim, F. G.; Costello, C. E. Tandem Mass Spectrometry for Structural Characterization of Proline-Rich Proteins: Application to Salivary PRP-3. Anal. Chem. 2002, 74, 4124-4132.

70. Sobott, F.; McCammon, M. G.; Robinson, C. V. Gas-Phase Dissociation Pathways of a Tetrameric Protein Complex. Int. J. Mass Spectrom. 2003, 230, 193-200.

71. Volny, M.; Elam, W. T.; Ratner, B. D.; Turecek, F. Preparative Soft and Reactive Landing of Gas-Phase Ions on Plasma-Treated Metal Surfaces. Anal. Chem. 2005, 77, 4846-4853.

72. Alvarez, J.; Futrell, J. H.; Laskin, J. Soft-Landing of Peptides onto Self-Assembled Monolayer Surfaces. J. Phys. Chem. A 2006, 110, 1678 1687 